\title{
Identification and cloning of two insecticidal protein genes from Bacillus thuringiensis strain S185
}

\author{
Haitao $\mathrm{Li}^{1,2 \#}$, Chuanying $\mathrm{Du}^{1 \#}$, Dengxue Cui ${ }^{1 \#}$, Rongmei Liu ${ }^{1}$ and Jiguo $\mathrm{Gao}^{1 *}$ \\ ${ }^{1}$ Northeast Agricultural University, HarBin 150030, People's Republic of China. \\ ${ }^{2}$ State Key Laboratory of Biology for Plant Diseases and Insect Pests, Institute of Plant Protection, Chinese Academy of \\ Agricultural Sciences, Beijing 100094, People's Republic of China.
}

Received 12 April, 2014; Accepted 2 June, 2014

\begin{abstract}
Bacillus thuringiensis (Bt) is the most widely applied type of microbial pesticide due to its high specificity and environmental safety. The activity of $\mathrm{Bt}$ is largely attributed to the insecticidal crystal protein encoded by the cry genes. Different insecticidal crystal proteins of Bt have different bioactivity against distinct agricultural insect pests, and combination of these proteins not only increases insecticidal activity, but also overcomes and delays development of resistance. A Bt strain, S185, was isolated from a soil sample collected in Songfeng Shan district, Heilongjiang Province, China. Bt S185 has highly specific insecticidal activity against Coleoptera, and was determined to contain cry8-type genes by peptide mess fingerprint (PMF) analysis. Application of polymerase chain reaction-restricted fragment length polymorphisms (PCR-RFLP) analysis further determined the genotype due to the high homology of cry8Ea1 and cry8Fa1 genes. Through the full-length primers design, two insecticidal crystal protein genes cry8Ca and cry8Ea were obtained. Using prokaryotic cloning vectors, the recombinant plasmids $\mathrm{pEB}-\mathrm{cry} 8 \mathrm{Ca}$ and $\mathrm{pEB}$-cry8Ea were transferred into expression host strain Escherichia coli Rosetta, thus the two genes were successfully expressed in heterologous bacteria.
\end{abstract}

Key words: Bacillus thuringiensis, peptide mess fingerprint, identification, clone, insecticidal crystal protein.

\section{INTRODUCTION}

Bacillus thuringiensis $(\mathrm{Bt})$ is a gram-positive soil bacterium characterized by its ability to produce crystalline inclusions named cry or cyt during sporulation (Höfte and Whiteley, 1989). These inclusions consist of proteins with highly specific insecticidal activity (Aronson et al., 1986; Whiteley and Schnepf, 1986). The insecticidal spectrum varies within the 82 different serotypes reported (Lecadet et al., 1999), and affects insects primarily from the orders Lepidoptera, Diptera and Coleoptera (Rasko et al., 2005). There are also reports of Bt active against mosquitoes (Orduz et al., 1995).

Up to August 2013, 712 cry and 38 cyt proteins have been identified, of which 49 are cry8-type proteins, which consist of 1160 to 1210 amino acids and have molecular weights of 128 to $137 \quad \mathrm{kDa}$ (http://www.lifesci.sussex.ac.uk/home/Neil_Crickmore/Bt/;

\footnotetext{
*Corresponding. E-mail: gaojiguo1961@hotmail.com.

\#These three authors contributed equally to this study.

Author(s) agree that this article remain permanently open access under the terms of the Creative Commons Attribution License 4.0 International License
} 
Shu et al., 2007; Yu et al., 2006). The cry8-type protein has specific insecticidal activity against a variety of Coleopteran pests such as Scarabaeidae, Curculionidae and Chrysomelidae. Many kinds of Scarabaeidae are major pests of crops and trees, due to the difficulty of prevention and control of soil-dwelling pests. Their larvae (white grub) are one of the largest underground pest groups and cause great damage to many plant species. In China, every year about 16.47 million hectares is affected by the larvae, in a serious year reaching 52.72 million hectares, with yield losses of about 20 to $40 \%$, 933 thousand $\mathrm{hm}^{2}$ peanuts were only planted in 2002, and there were serious occurrence area of more than 40 $\mathrm{hm}^{2}$; there was, economic losses of 600 million yuan (Wei et al., 1985; Wang et al., 2012). Therefore, it is of great importance to isolate and clone high-activity cry8-type genes for constructing engineered bacteria and genetically modified plants for prevention and control of Coleopteran pests.

In this context, it is essential to clone and express cry8 genes from new $\mathrm{Bt}$ isolates. The present study describes the identification, cloning and expression of cry8Ca and cry8Ea from a new indigenous isolate of Bt S185 strain, which has high-virulence against Holotrichia parallela.

\section{MATERIALS AND METHODS}

Bacterial strains, plasmids and growth conditions

\section{Bt}

The Bt strain $\mathrm{S} 185$ used in this study was isolated from soil obtained from Songfeng Shan district, Heilongjiang Province, China. The $1 \mathrm{~g}$ soil sample was suspended in $15 \mathrm{~mL}$ sterilized distilled water and shaken. After heat treatment at $80^{\circ} \mathrm{C}$ for $20 \mathrm{~min}$, the appropriately diluted upper-layer of the suspension was incubated on $1 / 2$ Luria Broth (LB) medium (0.5\% tryptone, $0.25 \%$ yeast extract and $0.5 \% \mathrm{NaCl} ; \mathrm{pH} 7.0$ ) at $30^{\circ} \mathrm{C}$ for three days. Colonies were examined microscopically for the presence of parasporal crystals (Hastowo et al., 1992). Bt strains were incubated in LB medium for three days with shaking at $30^{\circ} \mathrm{C}$ at 250 rpm (Maniatis et al., 1982).

\section{Escherichia coli}

The Institute of Plant Protection, Chinese Academy of Agricultural Sciences supplied E. coli JM109 as the cloning host and E. coli Rosetta as the expression host. The strains were grown in LB medium at $37^{\circ} \mathrm{C}$ for $12-16 \mathrm{~h}$.

\section{Plasmids}

pMD19-T (TaKaRa Biotechnology Company) was used as cloning vector. $p E B$ vector, an improvement of $p E T b l u e-2$ vector was used as the expression vector modified by CL Shu in 2009 (Changlong et al., 2009).

\section{Microscopy}

\section{Optical microscopy observation}

The tested strains were dyed with carbol fuchsin after cultivation on solid $1 / 2$ LB medium at $30^{\circ} \mathrm{C}$ for 2 dayd, and then examined under an oil immersion objective (Gundersen et al., 1988).

\section{Electron microscopy observation}

Spores and crystals of $B t \mathrm{~S} 185$ were collected by centrifugation at $12000 \mathrm{rpm}$ for $10 \mathrm{~min}$. The pellet was washed three times with distilled water, and suspended in phosphate buffer containing $3 \%$ glutaraldehyde, then dehydrated in dilute ethanol-propylene oxide series and embedded in an Epon resin mixture (Sangon Ltd. China). The sample was photographed by a New Bio-TEM electron microscope (Hitachi Ltd. Japan) operating at an accelerating voltage of $80 \mathrm{kV}$, after undergoing ultrathin sectioning by a Reichert ultramicrotome (Leika Aktiengesellschaft. Wien Austria) and staining with uranyl acetate and lead citrate.

\section{Plasmid DNA extraction}

Bt strain plasmid DNA extraction was as described by Song et al. (2003). The E. coli strain plasmid was prepared and further purified by a plasmid kit (Axygen Products), used according to the manufacturer's instructions. Plasmid profiles were determined for each strain by electrophoresis through $0.7 \%$ agarose gel.

\section{Protein analysis}

Bt S185 was grown with shaking at $180 \mathrm{rpm}$ at $30^{\circ} \mathrm{C}$ in $1 / 2 \mathrm{LB}$ medium until sporulation was complete, as determined by microscopy. The spores and crystals were harvested by isoelectric point deposition (Guo et al., 2005).

Recombinant $E$. coli cells were grown overnight at $37^{\circ} \mathrm{C}$ in $\mathrm{LB}$ containing ampicillin (amp). Bacterial cells were added to $200 \mathrm{ml}$ LB/amp $(200 \mu \mathrm{g} / \mathrm{ml})$ medium and shaken at $180 \mathrm{rpm}$ at $25^{\circ} \mathrm{C}$ to an OD600 of 0.6 to 0.7 (Srimonta et al., 2012). Expression was induced by adding $0.1 \mathrm{mM}$ isopropyl- $\beta$ - $d$-thiogalactoside (IPTG) at low temperature $\left(20^{\circ} \mathrm{C}\right)$ for $6 \mathrm{~h}$. The cells were gathered by centrifugation at $8000 \mathrm{rpm}$ for $10 \mathrm{~min}$ at $4^{\circ} \mathrm{C}$. For experiments, the cells were resuspended in TE buffer $(20 \mathrm{mM}$ Tris, $1 \mathrm{mM}$ EDTA, $\mathrm{pH}$ 8.0) and lysed using ultrasonic waves, repeated the $3 / 3 \mathrm{~s}$ intervals until the clock reached $10 \mathrm{~min}$. The supernatant was collected and the precipitate was suspended in TE buffer; both stored at $-20^{\circ} \mathrm{C}$.

Sodium dodecyl sulfate polyacrylamide gel electrophoresis (SDSPAGE) was performed on $8 \%$ gel as described by Laemmli (1970). The molecular weights were estimated by comparison with the protein ladder (GenStar Biosolutions Co. Ltd).

Protein samples used for PMF were derived from SDS-PAGE. The enzymatic digestion was performed as described by Fernandez et al. (1998) and Gharahdaghi et al. (1999). Mass spectrometric analysis was done by the Beijing Genomics institution Co. Ltd.

\section{Cloning and expressing of insecticidal crystal protein gene.}

Total DNA of S185 was isolated as described by lizuka et al. (1981). Primers were generated based on the published sequence of cry $8 \mathrm{Ca}$ and cry8Ea genes. The primer sequences used in this study were as follows (SangonCo.Ltd): cry8C5:5'ATGAGTCCAAATAATCAAAATG3';

cry8C3:5'TTACTCTTCTTCTAACACGAGTTC3'; cry8E5:5'ATGAGECCAAATAATCAAAATG3';

cry8E3:5'TTACTCTACGTCAACAATCAATTC3'.

PCR was carried out for 30 cycles under the following conditions: $94^{\circ} \mathrm{C}$ for $5 \mathrm{~min}, 94^{\circ} \mathrm{C}$ for $30 \mathrm{~s}, 52^{\circ} \mathrm{C}$ for $60 \mathrm{~s}, 72^{\circ} \mathrm{C}$ for $2 \mathrm{~min}$ and $72^{\circ} \mathrm{C}$ for $10 \mathrm{~min}$. Restriction digestion and ligation were carried out as per the manufacturer's instructions (TaKaRa Biotechnology 

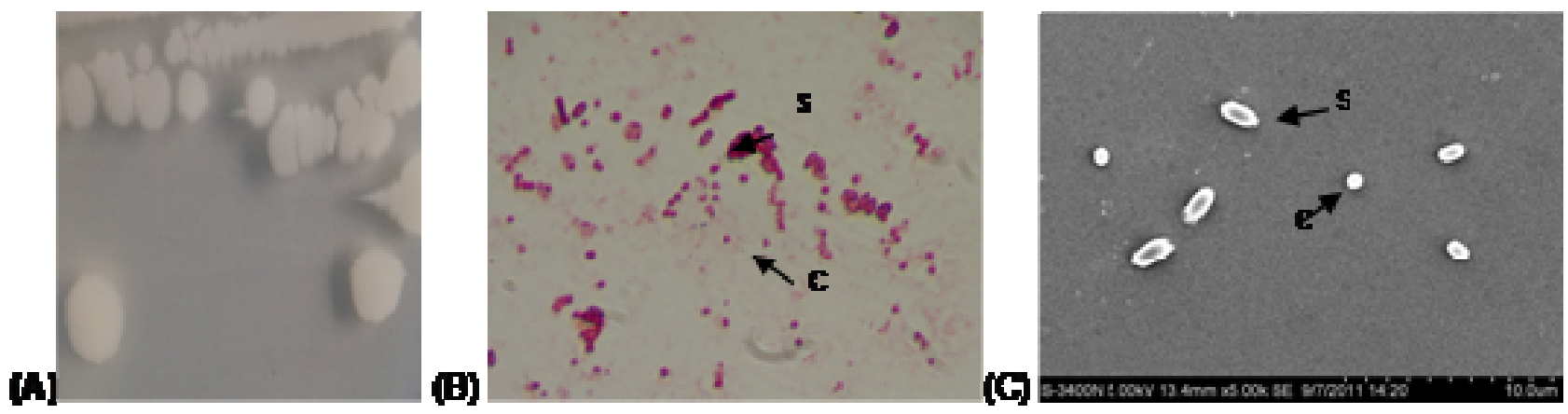

Figure 1. (A)The colony form of S185, Optical (B) and scanning electron (C) microscope image of Bt S185 strain. S, Spores; C, crystals.

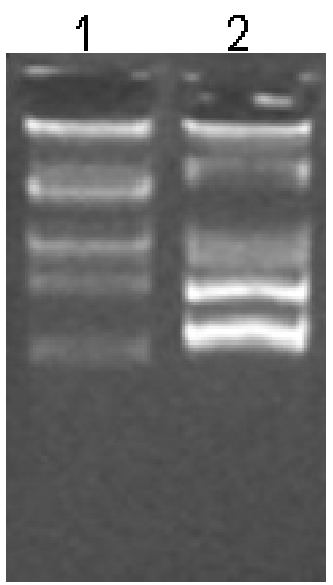

Figure 2. Plasmid DNA pattern of $\mathrm{S} 185$ and $B t$ subsp. kurstaki HD-73. Lane 1, Bt S185; lane 2, HD-73. The DNA fragments were electrophoresed on $0.7 \%$ agarose gel.

Company). Preparation of E. coli competent cells was as per the standard procedure (Sambrook et al., 1989). Vectors were inserted with approximately 3.7-kb target fragments, and then transformed into the $E$. coli host performed as described previously by Lenin et al. (2001). Positive recombinant-clones were selected by blue-white selection.

\section{Insect toxicity assay}

The toxicity of purified Bt S185 crystal was tested on larvae of $H$. parallela, $H$. oblita and Anomala corpulenta Motschulsky. Bioassays were performed in 24-well culture plates with $2-\mathrm{cm}^{2}$ wells. Purified crystal protein of $\mathrm{S} 185$ was suspended in distilled water to a final concentration of $10 \mathrm{~g} / \mathrm{L}$. Serial dilutions of crystals were tested by bioassay against $H$. parallela larvae. Bioassays were repeated three times. Larval mortality was recorded after $48 \mathrm{~h}$, and concentrations causing $50 \%$ mortality were determined by Probit analysis. Lethal concentrations were expressed per $\mathrm{cm}^{2}$ of surface.

\section{GenBank accession number}

The nucleotide sequence data published in this paper, cry8Ca and cry8Ea, were assigned GenBank accession numbers ADB54826 and JQ837282, respectively.

\section{RESULTS}

\section{Optical and electron micrograph observation of $B t$ S185}

After incubation for $48 \mathrm{~h}$ in $1 / 2$ LB medium, Bt S185 formed a single milky colony with neat edges. The colony was of a thin circular or nearly circular disk somewhat thicker in the center (Figure 1A). The vegetative masses of the colony were long rod-shapes under the oil immersion objective. However, the spores were stick-like and the crystals were spherical (Figure 1B and C).

\section{Plasmid and protein profile analysis of Bt S185}

The plasmid profile of $B t S 185$ showed five bands, which was found to be clearly different from $B t$ subsp. kurstaki HD73 (Figure 2), especially in regard to the small plasmid bands. Protein profile analysis of Bt $\mathrm{S} 185$ showed a 130 $\mathrm{kDa}$ protein band (Figure 3).

\section{Insect toxicity assays and the physiological and biochemical characteristics of S185}

The corrected mortality rate of $B t \mathrm{~S} 185$ for larvae of $H$. parallela, $H$. oblita and $A$. corpulenta Motschulsky were all $>50 \%$. Analysis of the data showed that the highest mortality rate of different concentrations of S185 protein against larva of $H$. parallela was $85.1 \%$. Purified S185 protein against $H$. parallela larvae had $\mathrm{LC}_{50}$ of 0.335 $\mu \mathrm{g} / \mathrm{ml}, 95 \%$ limiteds $(0.141-0.518 \mu \mathrm{g} / \mathrm{ml})$. 


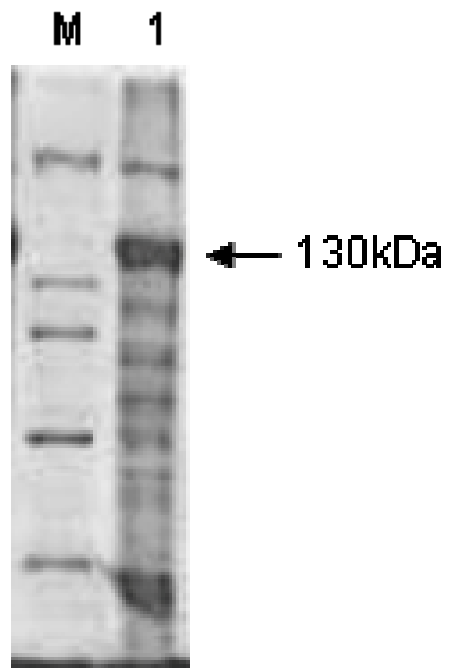

Figure 3. Sodium dodecyl sulfate-polyacrylamide gel electrophoresis profile of parasporal inclusion proteins from S185. Lane 1, S185 parasporal inclusion protein $\mathrm{M}$ : molecular weight marker. SDS was performed on an $8 \%$ gel. Spore crystal mixture obtained from the $20 \mathrm{ml}$ culture was suspended in $200 \mathrm{ml}$ of sterile distilled water. $5 \mu \mathrm{l}$ of each sample was analyzed.

\section{Peptide mass fingerprint and PCR-RFLP analysis of cry-type genes from Bt S185}

With the homology comparison of the peptide fragment in the $\mathrm{NCBI}$ database, PMF of Bt $\mathrm{S} 185$ crystal protein preliminarily showed that the crystal protein produced by S185 strain contained cry8Ca-type and cry8Ea-type or cry8Fa-type genes (Figure 4). Using PCR-RFLP of cry8type genes from $\mathrm{S} 185$, the primers for full-length genes were based on the encoding region of the known cry8Ca and cry8Ea genes in GenBank. With the strategy described in the Materials and Methods, a 3.7-kb fragment of cry8Ca and the same amount of cry8Ea were isolated from $B t \mathrm{~S} 185$. As cry8Ea has very high homology to cry8Fa and a close score was obtained with the PMF, PCR-RFLP was used to make a distinction. Analysis by DNAMAN showed that the full-length cry8Ea had two EcoRI site, 1148 and 2056 respectively. The completely digested cry8Ea fragments were 893, 908 and $1288 \mathrm{bp}$. However, the full-length cry8Fa had two EcoRI sites on 1572 and 2235, thus the completely digested fragments would be 663, 893 and 1572 bp. Therefore, enzyme action by EcoRI will distinguish cry8Ea from cry8Fa. There were obvious bands at 900 and $1200 \mathrm{bp}$ on the restriction enzyme map instead of $663 \mathrm{bp}$ (Figure 5), thus cry8Fa was not contained in the Bt S185 strain.
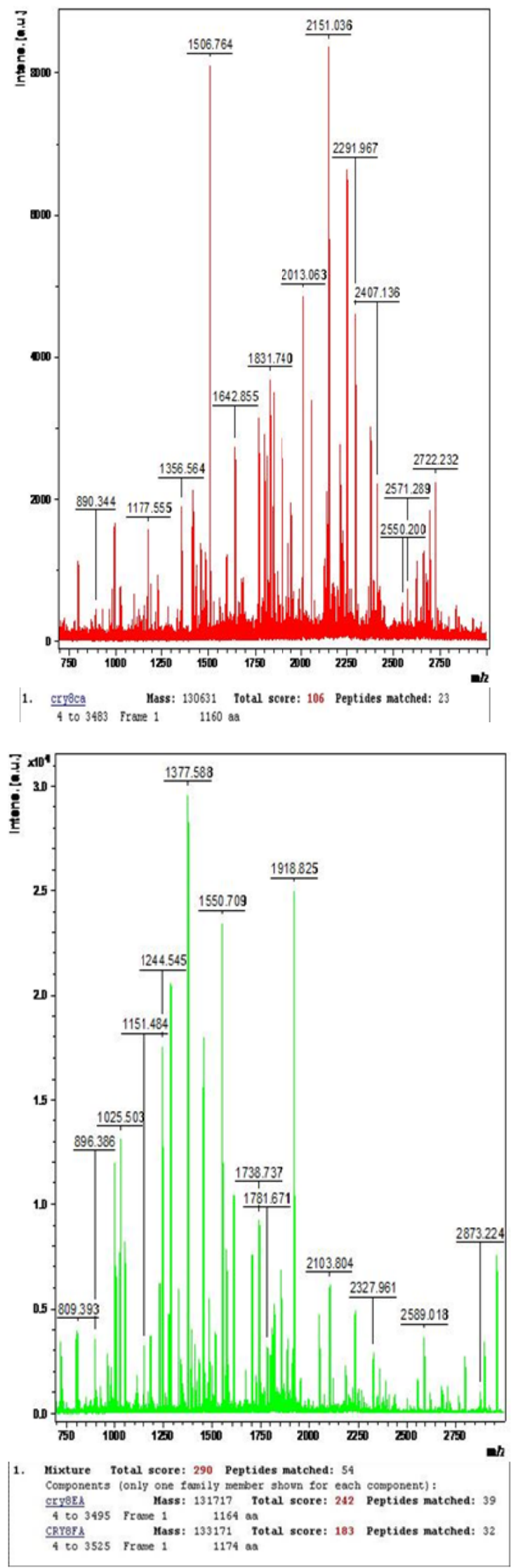

Figure 4. PMF analysis of S185 crystal protein. 


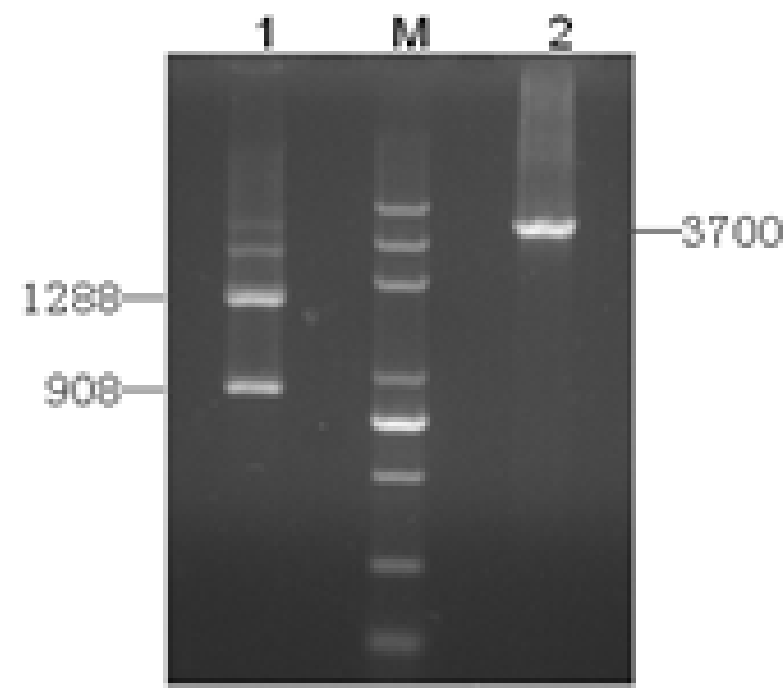

Figure 5. B. thuringiensis strain $\mathrm{S} 185$ after polymerase chain reaction (PCR)-restriction fragment length polymorphism analysis. S185 PCR products and PCRRFLP patterns (using cry8Ea-specific primers) Lane 1, PCR-RFLP patterns of cry8Ea, digested with endonucleases EcoRI; lane 2, PCR products of cry8Ea.

\section{Cloning and expression of the crystal protein genes}

The recovered PCR product was separately selected and cloned into $\mathrm{pEB}$ vector as stated; termed the recombinant plasmids $\mathrm{pEB}-8 \mathrm{Ca}$ and $\mathrm{pEB}-8 \mathrm{Ea}$. By sequencing the recombinant plasmids $p E B-8 C a$ and $p E B-8 E a$, the overall length sequences cry8Ca and cry8Ea were obtained. The predicted amino acid sequence of the cloned gene was analyzed to identify any similarities to other known protein sequences of cry and cyt toxins on NCBI. The cry8Ca protein contained 1160 amino acids and had a molecular weight of $130.25 \mathrm{kDa}$. The cry8Ca protein was acidic, its isoelectric point was 4.85 and its amino acid sequence shared $99 \%$ similarity with that of three other cry8Ca proteins. This protein therefore belongs to a new class of $B t$ crystal proteins, named cry $8 \mathrm{Ca}$ by the $B$. thuringiensis Delta-endotoxin Nomenclature Committee. In addition, the cry8Ea crystal protein showed $100 \%$ sequence identity to the cry8Ea1 crystal protein and contained 1140 amino acids with a molecular weight of $128.97 \mathrm{kDa}$. This protein was also acidic and its isoelectric point was 4.85. These two sequences are also assigned in the GenBank database.

The recombinant plasmids $\mathrm{pEB}-8 \mathrm{Ca}$ and $\mathrm{pEB}-8 \mathrm{Ea}$ were transformed into the expression host $E$. coli Rosetta, after being transformed into E. coli JM109 for propagation. Expression of the toxin proteins of $E$. coli were induced by addition of IPTG and were collected by centrifugation. SDS-PAGE showed that proteins of molecular mass of 130.25 and $128.97 \mathrm{kDa}$ were highly expressed in E. coli by pEB vector (Figures 6 and 7).

\section{DISCUSSION}

In recent years, the serious damage caused by Coleopteran pests has increased attention on developing new insecticidal crystal proteins against them. As reported, cry8-type toxins are insecticidal to a number of Coleopteran pests, especially certain species of scarabs (Michaels et al., 1996; Ogiwara et al., 1995; Sato et al., 1994; Shin-ichiro et al., 2003; Yamaguchi et al., 2008). Various insecticidal crystal proteins against Coleoptera have been patented, such as cry8Aa1, cry8Ba1, cry8Ca2, cry8Da2, cry8Ea1, cry8Fa1, cry8Ga1 cry8Ha1 and cry8Na1 (Abad et al., 2002; Feng et al., 2008; Michaels et al., 1996; Song et al., 2007), and some of them have already been used for development of biological pesticides and research on transgenic plants (Feng et al., 2008; Bixby et al., 2007). Thus, new cry8type genes have great application potential and broad application prospects.

Currently, peptide mass fingerprinting technology is used less in insecticidal gene identification. This method can quickly detect the insecticidal protein of a strain by directly comparing the similarity of peptides, and is an effective way to explore novel insecticidal protein genes with high reliability and ease of operation. However, because the current $B t$ insecticidal protein peptide database is incomplete, the peptide mass fingerprinting cannot distinguish high homology insecticidal proteins. In the present study, the peptide mass fingerprinting could not distinguish any cry8Ea or cry8Fa toxins that $B t \mathrm{~S} 185$ contained, so PCR-RFLP and sequencing were used for further identification of insecticidal protein genes. The combination of peptide mass fingerprinting, PCR-RFLP and sequencing technique successfully cloned and expressed two novel insecticidal protein genes from a high-activity insecticidal Bt strain.

\section{Conflict of Interests}

The author(s) have not declared any conflict of interests.

\section{ACKNOWLEDGMENTS}

We are grateful to the Institute of Plant Protection, HeBei CangZhou Academy of Agricultural Sciences for bioassay. This study was supported by grants from the National High Technology Research Development Program (863 Program) (Grant No. 2011aa10a203), National Natural Science Foundation for Genetically Modified Organisms Breeding Major Program (Grant No. 2014ZX0800913B-002), Project for National Basic Science Personnel Training Foundation (Grant No. J1210069), Scientific Research Foundation for the Doctoral Program of Northeast Agricultural University (Grant No. 2010RCB54), the open fund of State Key Laboratory of Biology for Plant Diseases and Insect Pests 


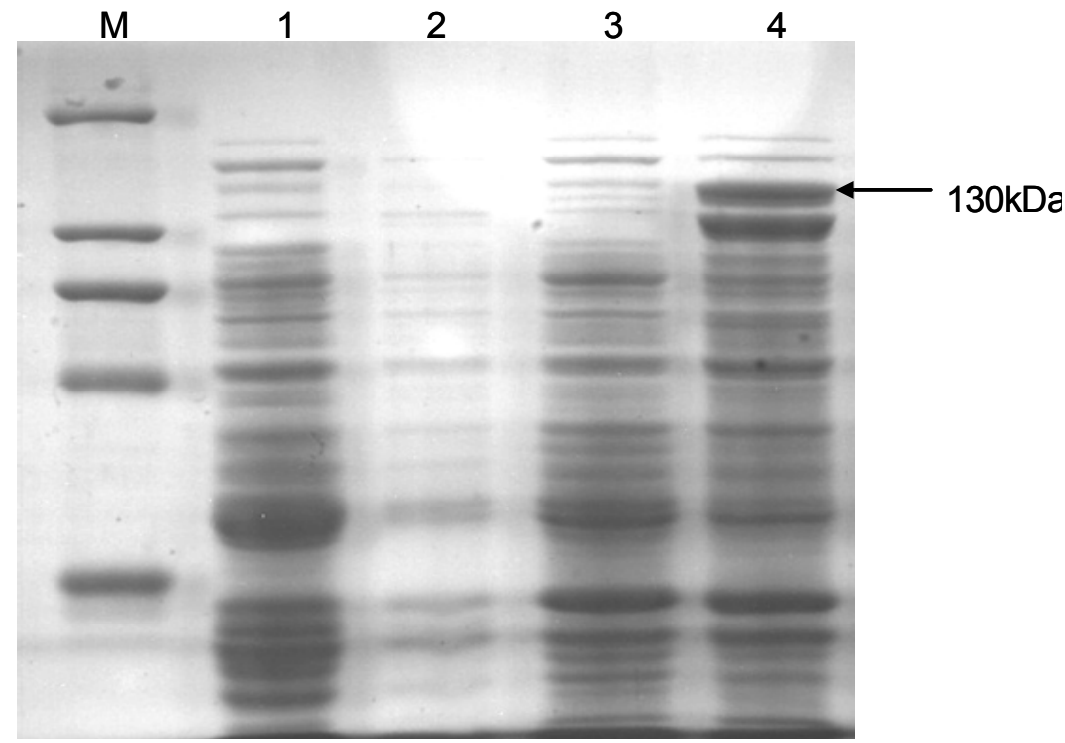

Figure 6. The SDS-PAGE profile of cry8Ea1 proteins from E. coli Rosetta. Lane 1, empty gsensor pEB; lane 2, induced empty gsensor pEB; lane 3, cry8Ea1 in Rosetta without induced; lane 4, cry8Ea1 in Rosetta with induced.

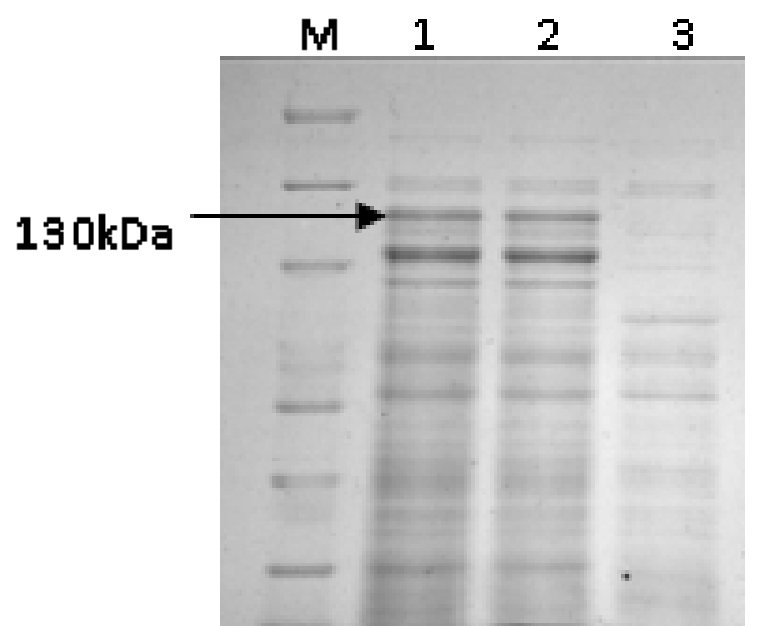

Figure 7. The SDS-PAGE profile of cry8Ca4 proteins from E. coli Rosetta. Lane 1, supernatant of cry8Ca4 in Rosetta; Lane 2, sediment of cry8Ca4 in Rosetta; Lane 3 , empty gsensor $\mathrm{pEB}$.

(SKLOF201405) and the open fund of Key Laboratory of Ministry of Education of soybean biology.

\section{REFERENCES}

Abad AR, Duck NB, Feng X (2002). Genes encoding novel proteins with pesticidal activity against coleopterans. US Patent 8188036

Aronson Al, Beckman W, Dunn P (1986) Bacillus thuringiensis and related insect pathogens. Microbiol. Rev. 50:1

Bixby A, Alm SR, Power K, Grewal P, Swier SR (2007). Susceptibility of four species of turfgrass-infesting scarabs (Coleoptera:
Scarabaeidae) to Bacillus thuringiensis serovar japonensis strain Buibui. J. Econ. Entomol. 100:1604-1610

Changlong S, Hong Yu, Rongyan Wang, Shuliang Fen, Xudong Su, Dafang Huang, Jie Zhang,Fuping Song (2009). Characterization of Two Novel cry8 Genes from Bacillus thuringiensis Strain BT185. Curr. Microbiol. 58:389-392.

Feng SL, Song F, Zhang J, Shu CL, Wang RY, Lang ZH, Huang DF (2008).Efficient Bacillus thuringiensis cry8h gene, protein for vaginata destructive insect and uses of the same. CN Patent 101130762A

Fernandez J, Gharahdaghi F, Mische SM (1998). Routine identification of proteins from sodium dodecyl sulfate-polyacrylamide gel electrophoresis (SDS-PAGE) gels or polyvinyl difluoride membranes using matrix assisted laser desorption/ionization-time of flight-mass spectrometry (MALDI-TOF-MS). Electrophoresis 19: 1036-1045.

Gundersen HJG, Bagger P, Bendtsen TF, et al (1988). The new stereological tools: disector, fractionator, nucleator and point sampled intercepts and their use in pathological research and diagnosis. APMIS 96:857-881

Guo AY, Wang S (2005). Extraction of crystal protein from Bacillus thuringiensis. Food Ferment. Ind. 31:8-10

Hastowo S, Lay BW, Ohba M (1992). Naturally occurring Bacillus thuringiensis in Indonesia. J. Appl. Microbiol. 73:108-113

Höfte H, Whiteley HR (1989). Insecticidal crystal proteins of Bacillus thuringiensis. Microbiol. Rev. 53:242-255

lizuka T, Faust RM, Travers RS (1981). Isolation and partial characterization of extrachromosomal DNA from serotypes of Bacillus thuringiensis pathogenic to lepidopteran and dipteran larvae by agarose gel electrophoresis. J. Sericult. Sci. Jpn 50:120-133

Gharahdaghi F, Weinberg CR, Meagher DA, Imai BS, Mische SM (1999). Mass spectrometric identification of proteins from silverstained polyacrylamide gel: a method for the removal of silver ions to enhance sensitivity. Electrophoresis 20(3): 601-605.

Laemmli UK (1970). Cleavage of structural proteins during the assembly of the head of bacteriophage T4. Nature 227:680-685

Lecadet MM, Frachon E, Dumanoir VC, Ripouteau H, Hamon S, Laurent $\mathrm{P}$, Thiery I (1999). Updating the $\mathrm{h}$ - antigen classification of Bacillus thuringiensis. J. Appl. Microbiol. 86:660-672

Lenin K, Asia MM, Udayasuriyan V (2001). Expression of cry2aa gene in an acrystalliferous Bacillus thuringiensis strain and toxicity of cry2aa against Helicoverpa armigera. World J. Microbiol. Biotechnol. $17: 273-278$ 
Maniatis T, Fritsch EF, Sambrook J (1982). Molecular clonings: a laboratory manual. Cold Spring Harbor Laboratory, Cold Spring Harbor, NY

Michaels TE, Narva KE, Foncerrada L (1996). Bacillus thuringiensis toxins active against scarab pests. US Patent 5554534

Ogiwara K, Hori H, Minami M, Takeuchi K, Sato R, Ohba M, Iwahana, H (1995). Nucleotide sequence of the gene encoding novel deltaendotoxin from Bacillus thuringiensis serovar japonensis strain buibui specific to scarabaeid beetles. Curr. Microbiol. 30:227-235

Orduz S, Restrepo N, Patiño MM, Rojas W (1995). Transfer of toxin genes to alternate bacterial hosts for mosquito control. Memórias Do Instituto Oswaldo Cruz 90:97-107

Rasko DA, Altherr MR, Han CS (2005). Genomics of the Bacillus cereus group of organisms. FEMS Microbiol. Rev. 29:303-329

Sambrook J, Fritch EF, Maniatis T (1989). Molecular cloning: a laboratory manual, 2nd edn. Cold Spring Harbour Laboratory Press, New York. Vol. 1-3.

Sato R, Takeuchi K, Ogiwara K (1994). Cloning, heterologous expression, and localization of a novel crystal protein gene from Bacillus thuringiensis serovar japonensis strain buibui toxic to scarabaeid insects. Curr. Microbiol. 28:15-19

Shin-ichiro A, Yamashita C, lizuka T, Takeuchi K, Yamanaka S, Cerf D, Yamamoto T (2003). A strain of Bacillus thuringiensis subsp. galleriae containing a novel cry8 gene highly toxic to Anomala cuprea (Coleoptera: Scarabaeidae). Biol. Control 28:191-196

Shu C, Liu R, Wang R, Zhang J, Feng S, Huang D, Song F (2007). Improving toxicity of Bacillus thuringiensis strain contains the cry8Ca gene specific to Anomalacorpulenta larvae. Curr. Microbiol. 55:492496.

Song FP, Zhang J, Feng SL, et al. (2007). Bacillus thringiensis strain and gene with high effect on coleoptera pests.CN Patent 1323159C.
Song FP, Zhang J, Gu A, Wu Y, Han LL, He KL, Chen ZY, Yao J, Hu YQ, Li GX, Huang DF (2003). Identification of cry1l-type genes from Bacillus thuringiensis strains and characterization of a novel cry1/type gene. Appl. Environ. Microbiol. 69:5207-5211

Srimonta GY, Munshi AH, Soumitra KS (2012). Identification of the bioactive core component of the insecticidal Vip3A toxin peptide of Bacillus thuringiensis. J. Plant Biochem. Biotechnol. 21:128-135

Wang YD, Xiao C, Yin J, Cao YZ, Li K (2012). Evaluation of the impacts on infection ability of entomopathogens nematodes to Grub, Holotrichia parallela for three chemical pesticides. Chin. J. Biol. Control 28(1):67-73

Wei HJ, Zhang ZL, Wang YC (1985). Chinese underground pests. Shanghai Science and Technology Press, China

Whiteley HR, Schnepf HE (1986). The molecular biology of parasporal crystal body formation in Bacillus thuringiensis. Annu. Rev. Microbiol. 40:549-576.

Yamaguchi T, Sahara K, Bando H, Asano SI (2008). Discovery of a novel Bacillus thuringiensis cry8D protein and the unique toxicity of the cry8D-class proteins against scarab beetles. J. Invertebrate Pathol. 99:257-262

Yu H, Zhang J, Huang D et al (2006). Characterization of Bacillus thuringiensis strain Bt185 toxic to the Asian cockchafer: Holotrichiaparallela. Curr. Microbiol. 53:13-17 